\title{
Políticas e práticas de saúde \\ rumo à equidade: \\ uma abordagem geral*
}

LAS POLÍTICAS Y PRÁCTICAS DE SALUD RUMBO A LA EQUIDAD: UN ABORDAJE GENERAL

\section{Emiko Yoshikawa Egry', Rosa Maria Godoy Serpa da Fonseca², Maria Amélia de Campos Oliveira ${ }^{3}$, Maria Rita Bertolozzi ${ }^{4}$, Renata Ferreira Takahashi ${ }^{5}$, Suely Itsuko Ciosak ${ }^{6}$, Anna Maria Chiesa ${ }^{7}$, Lúcia Yasuko Izumi Nichiata ${ }^{8}$, Eunice Nakamura ${ }^{9}$}

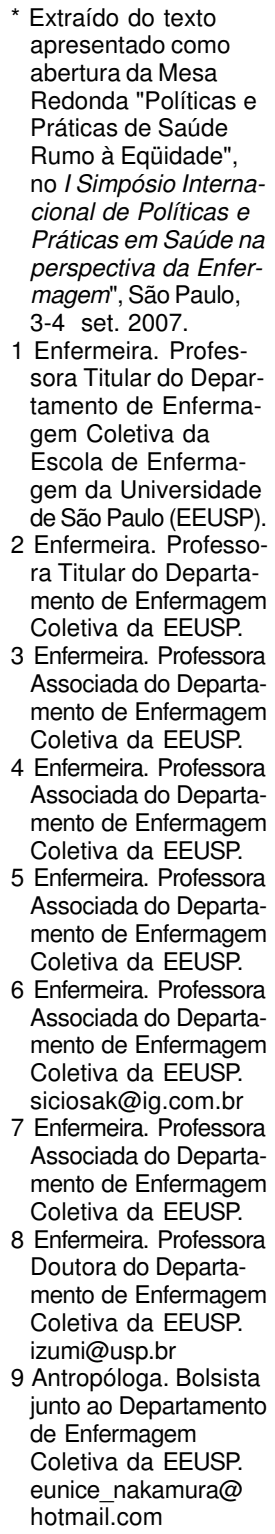

3 Enfermeira. Professora Associada do Departamento de Enfermagem Coletiva da EEUSP.

4 Enfermeira. Professora Associada do Departamento de Enfermagem Coletiva da EEUSP.

5 Enfermeira. Professora Associada do Departamento de Enfermagem Coletiva da EEUSP.

6 Enfermeira. Professora Associada do Departamento de Enfermagem Coletiva da EEUSP. siciosak@ig.com.br

7 Enfermeira. Professora Associada do Departamento de Enfermagem Coletiva da EEUSP.

8 Enfermeira. Professora Doutora do Departamento de Enfermagem Coletiva da EEUSP. izumi@usp.br

9 Antropóloga. Bolsista junto ao Departamento de Enfermagem Coletiva da EEUSP. eunice_nakamura@ hotmail.com

\section{RESUMO}

Trata-se de um texto introdutório ao debate sobre as políticas e práticas de saúde rumo à eqüidade. Inicia-se descrevendo suscintamente a forma como o Departamento de Enfermagem em Saúde Coletiva da Escola de Enfermagem da Universidade de São Paulo desenvolveu suas ações para apoiar o enfrentamento das iniqüidades em saúde. Finalmente abre perspectivas de compreensão diferenciada do conceito de eqüidade baseado na literatura atual. Cada um dos tipos de eqüidade enseja práticas e políticas distintas.

\section{DESCRITORES}

Equiidade.

Iniquidade social.

Políticas públicas.

Saúde pública.

Enfermagem.

\section{ABSTRACT}

This paper presents a preliminary overview of policies and practices in health focusing equity. It begins with a brief description of the actions developed by the Collective Health Nursing Department of the School of Nursing of the University of Sao Paulo, Brazil, to support the struggle for social equity. It also presents the different perspectives of the concept that can be identified in health literature, each of them shaping distinct policies and practices.

\section{KEY WORDS}

Equity.

Social inequity.

Public policies.

Public health.

Nursing.

\section{RESUMEN}

Este texto hace una introducción al debate sobre las políticas y prácticas de salud para el desafío de la equidad. Se describe sucintamente la forma como el Departamento de Enfermería en Salud Colectiva de la Escuela de Enfermería de la Universidad de São Paulo ejecutó sus acciones para apoyar el enfrentamiento de las iniquidades en salud. Finalmente, abren-se las perspectivas para una comprensión diferenciada del concepto de equidad, basada en la literatura actual. Cada uno de los tipos de comprensión de equidad abraza prácticas y políticas distintas.

\section{DESCRIPTORES}

Equidad.

Inequidad social.

Políticas públicas.

Salud pública.

Enfermería. 


\section{INTRODUÇÃO}

O Departamento de Enfermagem em Saúde Coletiva(ENS) da Escola de Enfermagem da Universidade de São Paulo (EEUSP) foi projetado por um grupo de docentes que pertenciam ao Departamento de Enfermagem Médico-Cirúrgica (ENC). A grande causa e força motriz para a abertura de um novo campo de teorias e práticas da enfermagem foi, sem dúvida, o enfrentamento das iniqüidades sociais, visualizadas na perspectiva da saúde. Assim, desde logo, nos seus diversos campos de atuação, o ENS colocou como horizonte a construção do conhecimento sobre eqüidade:

a) no ensino, no nível de graduação, o desafio foi propiciar uma transformação curricular que desse aos graduandos a possibilidade de ver e intervir nos determinantes sociais dos processos saúde-doença, compreendendo o individual e o coletivo como faces da mesma realidade objetiva, oferecendo-lhes instrumentos para intervir na singularidade, na particularidade e na estruturalidade dos $\operatorname{processos}^{(1)}$;

b) no ensino de pós-graduação senso estrito, o enfrentamento das iniqüidades foi feito por meio da criação da área de concentração de Enfermagem em Saúde Coletiva dentro do Programa de Pós-graduação em Enfermagem da EEUSP, assumindo a visão de mundo materialista histórica e dialética como a hegemônica para construir os saberes e as práticas em saúde coletiva. Mais recentemente, o ensino no nível de especialização em saúde coletiva com ênfase em saúde da família veio preencher uma importante lacuna na qualificação dos trabalhadores de saúde da atenção básica, tendo como pilares de sustentação os princípios originais do Sistema Único de Saúde (SUS) ${ }^{(2)}$;

c) no âmbito da extensão universitária buscou superar as contradições prioritariamente desenvolvendo projetos de integração docente-assistencial (IDA), tendo por base a mesma visão de mundo e realizada sob a forma de pesquisa participante. Quando da constituição do ENS e para dar conta do desafio exposto, a qualificação docente em saúde coletiva fazia-se necessária e urgente. A IDA representou um mergulho teórico-prático nas formas de ensinar e de intervir nos processos saúde-doença, assim como nos processos de trabalho instituintes de ambas as práticas;

d) no âmbito da construção do conhecimento, o ENS adotou a mesma postura crítica, quer nos recortes dos objetos de investigação, quer nas metodologias escolhidas, preferindo pesquisas em que, durante os processos de investigação, os sujeitos sociais pudessem de alguma forma ser inseridos em espaços de reflexão crítica. Mas não era só isso: fazia-se imperioso ter uma condução pedagógica organizada para que a reflexão crítica não terminasse em denuncismo e sim em intervenção nas contradições das realida- des consideradas, nas suas três dimensões, num movimento participativo e de empoderamento dos sujeitos sociais envolvidos.

\section{AS PERSPECTIVAS CONCEITUAIS E OPERACIONAIS DA EQÜIDADE}

O conceito de equidade é fundamental para a priorização das ações, tendo em vista a gradual diminuição das desigualdades sociais, pois há flagrante heterogeneidade da população no tocante às suas necessidades em saúde e acesso aos serviços ${ }^{(3-4)}$.

Mais do que o conceito de risco, o reconhecimento de chances de vida pode operacionalizar melhor o conceito de equidade para a saúde. Isto porque o conceito de risco remete mais aos aspectos biológicos, subsidiando ações de caráter individual, menos voltadas para o coletivo. Em oposição, o conceito de chances de vida remete ao reconhecimento das condições socioeconômicas e ambientais, além das políticas determinantes do processo saúde-doença da coletividade ${ }^{(5)}$.

A categoria espaço/ território é uma alternativa para estabelecer uma aproximação entre condições e qualidade de vida, a fim de entender o papel do Estado (e das políticas públicas) no atendimento das necessidades de reprodução social dos diferentes grupos sociais ${ }^{(6)}$.

Alguns autores ${ }^{(7-8)}$ identificaram três gerações de estudos sobre iniqüidades em saúde: a primeira dedicou-se a descrever as relações entre pobreza e saúde; a segunda, a descrever os gradientes de saúde de acordo com vários critérios de estrati-ficação socioeconômica e a terceira e atual geração dedica-se principalmente a explicitar os mecanismos de produção das iniqüidades.

O principal desafio dos estudos sobre as relações entre determinantes sociais e saúde

consiste em estabelecer uma hierarquia de determinações entre os fatores mais gerais de natureza social, econômica, política e as mediações através das quais esses fatores incidem sobre a situação de saúde de grupos e pessoas ${ }^{(7)}$.

Há autores ${ }^{(9)}$ que ressaltam a existência e a persistência das desigualdades tem sido objeto de estudo e de preocupação de formuladores das políticas, administradores de serviços de saúde e pesquisadores. Ao tema, foi incorporada a dimensão da justiça social, que permite analisar os diferentes tipos de desigualdade, remetendo à análise do político, incorporando valores éticos e morais explícitos nas bases contratuais de determinada sociedade.

Apesar da variedade conceitual, o estudo ${ }^{(10)}$ considera que há certo consenso hoje sobre o que é eqüidade em saúde: idealmente, todos os indivíduos de uma sociedade 
devem ter a justa oportunidade para desenvolver seu pleno potencial de saúde e, no aspecto prático, ninguém deve estar em desvantagem para consegui-lo. Mais que o conceito, o importante é o entendimento da desigualdade em saúde na perspectiva de justiça social.

Há outras discussões em curso sobre o entendimento de eqüidade, como por exemplo, a adotada no estudo ${ }^{(11)}$ que classifica os diferentes tipos de equidade em ontológica, de oportunidade, de condições e de resultados. Citando textualmente a autora do estudo:

eqüidade ontológica se refere à igualdade fundamental entre as pessoas. Varia das abordagens religiosas de igualdade perante Deus, passando pela abordagem marxista - para a qual a natureza do ser humano é forjada por sua práxis livre e transformadora, que busca um domínio cada vez maior sobre a natureza e maior comunicação, autonomia e consciência - até as perspectivas relativistas modernas, de que a natureza humana é específica de certas culturas e sistemas sociais. A eqüidade de oportunidade de se alcançar os objetivos almejados. Esta concepção, herança das revoluções francesa e americana, está na base da teoria social da meritocracia, sendo uma característica da doutrina política do liberalismo clássico, que considera ser possível uma mobilidade social perfeita, a partir da igualdade de oportunidades. Uma vez garantida a universalidade dos direitos fundamentais à vida, à liberdade e à propriedade, todos têm, independente de sua origem, as mesmas oportunidades de alcançar as mais altas posições individuais. Assim, de acordo com esta concepção, as posições na estrutura ocupacional da sociedade são preenchidas apenas pelo mérito pessoal, a partir da igualdade de oportunidades para o ingresso nas

\section{REFERÊNCIAS}

1. Breilh J. Nuevos conceptos y técnicas de investigación: guia pedagógica para un taller de metodología. Quito: Centro de Estudios y Asesoría en Salud (CEAS); 1995.

2. Brasil. Lei n. 8080, de 19 setembro 1990. Dispões sobre as condições para a Promoção, Proteção e Recuperação da Saúde, a organização e o funcionamento dos serviços correspondentes e dá outras providências [legislação na Internet]. Brasília; 1990. [citado 2007 set. 13]. Disponível em: http://portal.saude.gov.br/ portal/arquivos/pdf/LEI8080.pdf

3. Mendes EV. Importância de los sistemas locales de salud en la tranformación de los sistemas nacionales de salud. In: Paganini JM, Capote Mir R. Los sistemas locales de salud conceptos, métodos, experiências. Washington: OPS; 1990. p. 21-8. (Publicación Cientifica, 519).

4. Kadt E, Tasca R, Promovenod a equidade: u novo enfoque com base no setor da saúde. São Paulo: Hucitec; 1993.

5. Chiesa AM, Westphal MF, Kashiwagi NM. Geoprocessamento e a promoção da saúde: desigualdades sociais e ambientais em São Paulo. Rev Saúde Pública [periódico na Internet]. 2002[citado 2007 set 13];36(5):[cerca de 7 p.]. Disponível em: http: /www.scielo.br/scielo.php?script=sci_arttext\&pid=S0034$89102002000600004 \& \operatorname{lng}=\mathrm{pt}$ instituições sociais. [...] a igualdade de oportunidade é praticamente inseparável da noção de eqüidade de condições. Para haver, de fato, oportunidades iguais para todos os membros da sociedade, a eqüidade precisa ser observada também no "ponto de partida": apenas pessoas submetidas às mesmas condições de vida podem vir a ser consideradas "em igualdade" para competir com base em habilidades e méritos individuais. Esta é, sem dúvida, uma concepção mais completa e complexa, que possibilita a inclusão de aspectos estruturais na determinação do grau de mobilidade das diferentes classes sociais. Finalmente, o quarto tipo é a eqüidade dos efeitos ou resultados. Nele, a legislação e outras medidas políticas procuram compensar os efeitos das desigualdades de condições sociais. Mecanismos de discriminação positiva precisam operar em favor de grupos menos privilegiados que têm, assim, suas oportunidades aumentadas, assegurando a eqüidade nos resultados ${ }^{(11)}$.

\section{ABRINDO O TEMÁRIO PARA DEBATE}

Estas e outras reflexões, com certeza farão parte das falas dos nossos caros convidados para esta mesa redonda: o Secretário Adjunto da Secretaria de Estado da Saúde de São Paulo, o médico Renilson Rehen de Souza; a Professora Adjunta da Faculdade de Ciências Médicas da Santa Casa de Misericórdia de São Paulo, a Professora Doutora Rita Barradas Barata e a enfermeira, Professora Emérita da Universidade Federal de Minas Gerais, a Professora Doutora Roseni Rosangela de Sena. Agradeço a todos pela presença que com certeza abrilhantará o nosso evento de maneira ímpar.

6. Paim JS. Abordagens teórico-conceituais em estudos de condições de vida e saúde: notas para reflexão e ação. In: Barata RB, organizador. Condições de vida e situação de saúde. Rio de Janeiro: ABRASCO; 1997. p. 7-30.

7. Buss PM, Pellegrini Filho A. A saúde e seus determinantes sociais. Physis (Rio J.) [periódico na Internet]. 2007[citado 2007 set. 13];17(1):[cerca de 18 p.]. Disponível em: http://www. scielo.br/scielo.php?script=sci_arttext\&pid=S0103-7331200 $7000100006 \& \operatorname{lng}=\mathrm{pt}$

8. Krieger N. A glossary for social epidemiology. J Epidemiol Community Health. 2001;55(10):693-700.

9. Viana ALD'A, Fausto MCR, Lima LD. Política de saúde e eqüidade. São Paulo Perspect [periódico na Internet]. 2003[citado 2007 set. 13];17(1):[cerca de 11 p.]. Disponível em: http:// www.scielo.br/scielo.php?script=sci_arttext\&pid=S0102$88392003000100007 \& \operatorname{lng}=\mathrm{pt}$

10. Whitehead M. The concepts and principles of equity and health. Copenhagen: World Health Organization, Regional Office for Europe; 2000.

11. Duarte CMR. Eqüidade na legislação: um princípio do sistema de saúde brasileiro? Ciênc Saúde Coletiva. 2000;5(2):443-63. 